\title{
Aire de Ciudad
}

\author{
City Air \\ JESÚS MARINA BARBA \\ Doctor en Historia. Universidad de Granada \\ ELENA MoRón SERNa \\ Arquitecta. Universidad de Sevilla \\ azul@marinamoron.com
}

Recibido: $29 / 03 / 2014$

Aceptado: 14/04/2014

\section{Resumen}

Vacío, nada, invisible, aire... son temas cuya importancia en la evolución de las formas de modelización de la realidad -perspectiva, profundidad, tridimensionalidad, relación entre los objetos- resulta tan indiscutible como difícil e infrecuente de atender. Representar la ciudad supone conjugar los diferentes elementos que componen su paisaje, integrado tanto por sólidos visibles de presencia física como por la distancia, la relación y la articulación entre ellos. De la formulación de estas secuencias de lleno-vacío resultará una determinada comunicación del hecho urbano. Según esta lectura global, nos parecen bastante expresivas dos tendencias de la contemporaneidad fotográfica que han llegado a convertirse en auténticos estereotipos visuales.

Imágenes donde la rotundidad de la escala queda subrayada por la acumulación, y el encuadre cerrado alimenta la opresión de una trama asfixiante que se siente susceptible de extenderse hasta el infinito. O todo lo contrario. Entre los lugares más 
visitados por los fotógrafos, los espacios en desuso, lo obsoleto como espectáculo, la desolación y el abandono de un tiempo que se asume solo por ajeno. Nuestro sensor colectivo sigue almacenando, en número creciente, estos vacíos sobrevenidos, esta invasión o sustracción de aire que miramos con incómoda ansiedad.

Sería desproporcionado concluir que esta doble alternativa de pesadilla, de asfixia o de hiperventilación, define la producción de imágenes urbanas en la actualidad. Pero con el aire situado en el foco de nuestra atención, tendría que ser el momento ya de plantearnos la correspondencia entre estas líneas de fuerza de la creación visual y su reflejo como maneras de vivir lo urbano. Porque si una imagen es la representación de una percepción, deberíamos preguntarnos por las causas perceptivas de semejante polaridad de vacíos. La fuerza de mensajes como los referidos nos llevaría a formular la cuestión de en qué medida estos tópicos visuales, que pertenecen ya al universo de imágenes mentales de comprensión colectiva, están construyendo nuevos modos de percepción de lo urbano, tanto en el sentido de la densidad como en el de la desocupación.

\title{
Palabras clave
}

Arquitectura, fotografía, ciudad, vacío, imagen, representación.

\begin{abstract}
Emptiness, nothingness, invisibility, air... elements that are undoubtedly both important for the evolution of the different ways of modelling reality (in terms of perspective, depth, three-dimensionality and the relationship between objects) as well as ones whose address is both difficult and quite rare. Representing the city involves marrying the different elements making up its landscape, composed of physically present visible solid objects as well as the distance, relationship and the articulation existing among them. The formulation of these full-empty sequences will result in a particular way of interpreting the urban reality. According to this global interpretation, two trends in contemporary photography strike us as being particularly expressive, and ones that have managed to turn into authentic visual stereotypes.

Images where the roundness of scale is underlined by accumulation, and the close-up feeds into the stifling oppression of a suffocating plot that feels like it will go on until the end of time. However, it may have an equally different outcome. Disused, obsolete spaces serving as a stage, the desolation and abandonment of a time that can only be taken on from afar are among those places that are most frequented by photographers. Our collective sensor continues storing information in increasing numbers, these empty spaces that come at us from nowhere, this invasion or theft of the air that we go on observing with uncomfortable anxiety.
\end{abstract}


It would be disproportionate to conclude that this nightmarish two-fold alternative involving choking or hyperventilation defines how urban images are being produced today. However, considering how air is the very focus of our attention, this would appear to be the precise moment to consider the correspondence between these visual creation power lines and their reflection as an urban ways of living, because if an image can be a representation of a particular perception, we should ask ourselves the reason for the perceptual causes of such empty polarity. The force of messages such as those mentioned above would lead us to ponder the extent of how these visual topics, already belonging to the universe of mental images of collective understanding, build new ways of perceiving what is urban, both in the sense of density and in terms of disengagement.

\section{Keywords}

Architecture, photography, city, emptiness, image, representation.

Referencia normalizada: MARINA BARBA, JESÚS - MORÓN SERNA, ElENA (2014): “Aire de Ciudad". Arte y Ciudad. Revista de Investigación, no 5 (abril), págs. 41-51). Madrid. Grupo de Investigación Arte, Arquitectura y Comunicación en la Ciudad Contemporánea, Universidad Complutense de Madrid.

En julio de 1919 Marcel Duchamp, residente por entonces en los Estados Unidos, viaja durante algunos meses a Francia. De este periodo se conocen sus contactos con los círculos surrealistas y algunas de sus realizaciones conocidas como "ready-made". Una de éstas tiene su origen en el regalo que prepara para dejar a su amigo y mecenas Walter Arensberg en el momento de la despedida por su regreso a América. La ampolla de vidrio, que más tarde, desde 1949, deberá ser objeto de varias versiones, pasará del catálogo de accesorios de farmacia a la Historia del arte con el nombre, ya hoy tópico en el marketing del turismo cultural, de Aire de París.

La creación de Duchamp, como ha sido estudiado y analizado en numerosas ocasiones, encierra sugerentes lecturas acerca de lo conceptual en el desarrollo de las ideas artísticas y de la compleja relación artista-obra-espectador. Pero también, y por eso sirve de punto de partida para nuestra reflexión, significa aislar la representación de un tema cuya importancia en la evolución de 
las formas de modelización de la realidad -perspectiva, profundidad, tridimensionalidad, relación entre los objetos- resulta tan indiscutible como difícil e infrecuente de atender.

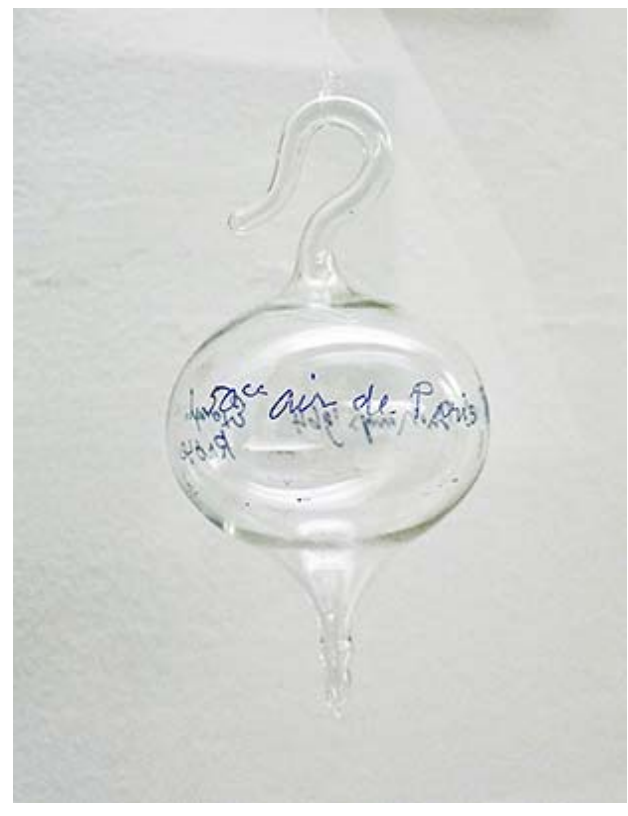

Fig. 1. Marcel Duchamp. Air de Paris, 1919. ( $4^{\mathrm{a}}$ v. 1964, Centre Pompidou, Paris) (Fotografía: _marina_morón. www.marinamoron.com)

La investigación interroga siempre a la contemporaneidad. Nos preguntamos acerca de nosotros mismos. Hacerlo en referencia al vacío tiene la fuerza paradójica que supone el situarnos en el terreno de nuestra propia condición. En un mundo convertido en espectáculo, vacío es cualquier cosa menos silencio y quietud. Un mundo lleno de vacíos. Parece normal que la dialéctica llenovacío se haya convertido en uno de los grandes temas de fondo de la sociedad actual. Nuestra época afronta un ejercicio que tiene mucho de revisión introspectiva: la reconsideración de las partes de la realidad que han quedado ocultas, marginadas por una visión desequilibrada a favor de la luz y lo lleno como entidades positivas. Pero todavía hoy, cuando la aritmética binaria ha llenado de ceros la tecnología de nuestra vida, y la física cuántica ha vuelto al concepto de no-materia para explicar la naturaleza del Universo, miramos con la desconfianza del oxímoron la existencia de este enigma invisible. Ciertamente, la historia del vacío está escrita a base de negaciones. Se trataría, más aún, de una negación forzada, obligado el ser humano por la necesidad de encontrar una 
respuesta y por la atracción magnética del interrogante. Que se trate de un tema tan esencial, vinculado de forma directa a bases científicas y filosóficas, no hace sino añadir trascendencia y angustia al problema.

Si el miedo derivó en visiones negativas, resulta igual de cierto que el mundo de la creación, intelectual y plástica, lo ha podido convertir en germen y motor de nuevas experiencias. De todos modos, sirva también como prevención, casi como antídoto, respecto de la retórica monocorde que invade las páginas de los textos que cantan, con sospechosa unanimidad, las excelencias plásticas y metafísicas del silencio-vacío. Su mayor coherencia, si se permite la ironía, es la vacuidad. Convendría revisitar periódicamente las ácidas reflexiones de Josep Quetglas, sus escritos contra la entronización de estos conceptos como esencia del arte moderno, sus llamadas a no confundir obras y nombres que poco tienen en común, a no atribuir la voluntad de no decir a lo que es expresión de incomunicación, de no querer decir, a no caer en las tentaciones de manual que olvidan que no todas las nadas son iguales porque cada época inventa su vacío y su silencio (Quetglas, 2001: 13).
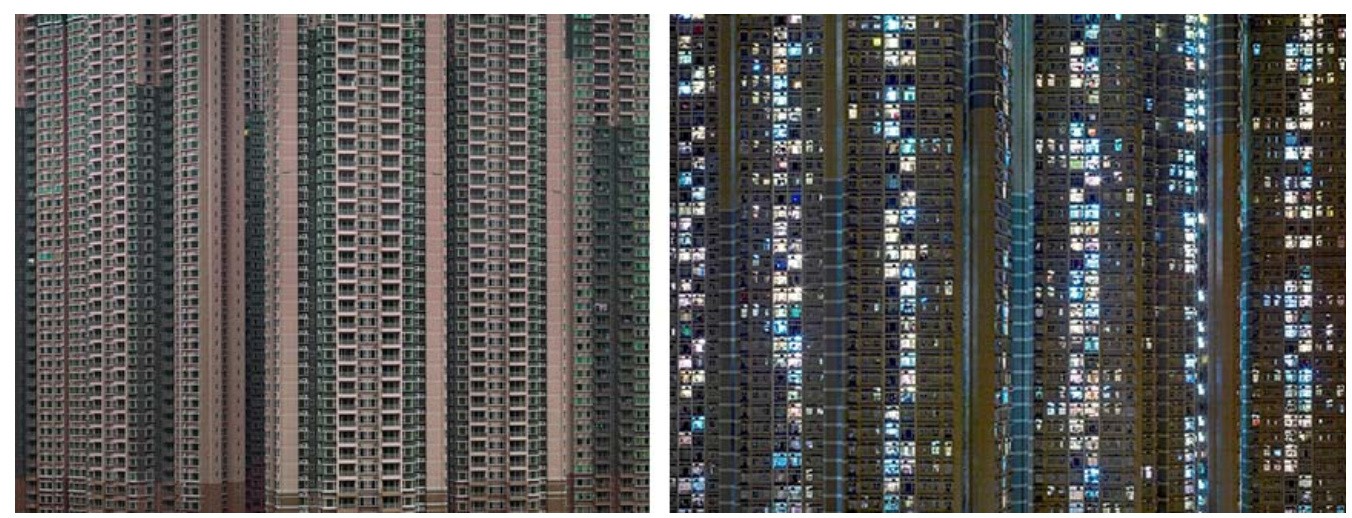

Fig. 2. Michael Wolf (2012), Architecture of density

(Wolf, Michael (2012), Architecture of density, Berlin, Peperoni books)

Representar la ciudad supone conjugar los diferentes elementos que componen su paisaje, integrado tanto por sólidos visibles de presencia física como por la distancia, la relación y la articulación entre ellos. De la formulación de estas secuencias de lleno-vacío resultará una determinada comunicación del hecho urbano. Según esta lectura global, nos parecen bastante expresivas dos 
tendencias de la contemporaneidad fotográfica que han llegado a convertirse en auténticos estereotipos visuales.

Imágenes como las de Michael Wolf o Stéphane Couturier aparecen una y otra vez en publicaciones de reportajes y documentos que pretenden dar noticia de las transformaciones experimentadas estos últimos años por las grandes aglomeraciones, sobre todo en Oriente. La rotundidad de la escala queda subrayada por la acumulación, y el encuadre cerrado alimenta la opresión de una trama asfixiante que se siente susceptible de extenderse hasta el infinito. La frontalidad de la perspectiva y la perfección técnica, cualquier atisbo de distorsión óptica está radicalmente prohibido, sustenta el mensaje de neutralidad, de manera que sea fácil identificar lo construido, por cámara y fotógrafo, y lo real, verificable en cualquier momento por la visión directa del viajero.
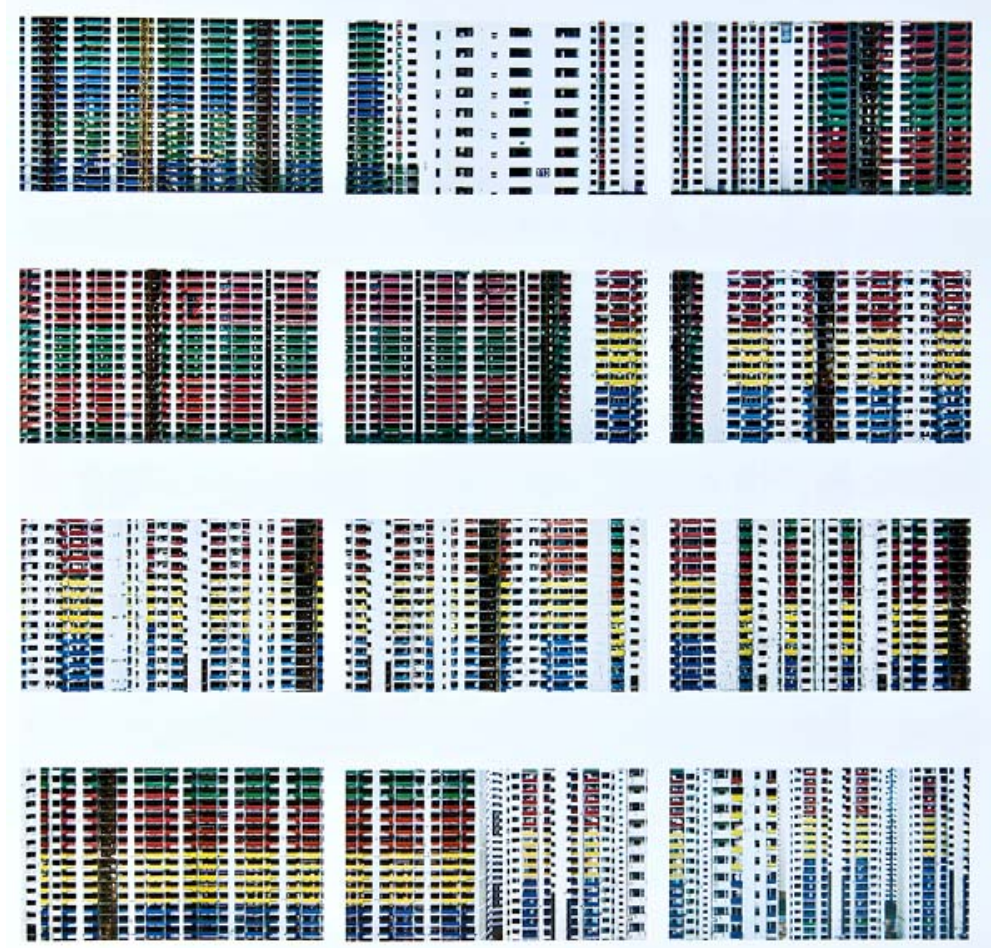

Fig. 3. Stéphane Couturier (2003-2010), Séoul-Tanji, video stills (VV.AA. (2011), High Rise Idea and Reality, Ostfildern, Hatje Cantz Verlag, p.30) 
Son imágenes que se diría de la ciudad de Argia, la que nos cuenta Italo Calvino (2005: 135), donde no hay aire:

Lo que hace a Argia diferente de las otras ciudades es que en vez de aire tiene tierra. La tierra cubre completamente las calles, las habitaciones están repletas de arcilla hasta el techo, sobre las escaleras se posa en negativo otra escalera, encima de los tejados de las casas descansan estratos de terreno como cielos sobre nubes.

Son fotografías que parecen aferrarse a la bidimensionalidad, hasta el extremo de negarse a sí mismas la función de su respiración interior, esa que consigne mediante la circulación de la mirada la construcción del espacio. Ciertamente, serían como una definición en negativo de la existencia de los adjetivos interiores. Cuando no es necesario, o no interesa, registrar el vacío, la compresión de la perspectiva dibuja una escena de planos yuxtapuestos. En ellas suena un discurso sin pausas, vemos, al haberse extraído el aire entre ellos, los objetos unidos, más yuxtapuestos que próximos, porque el lenguaje ha expulsado los silencios y no nos corresponde descifrar las claves ocultas de su articulación.

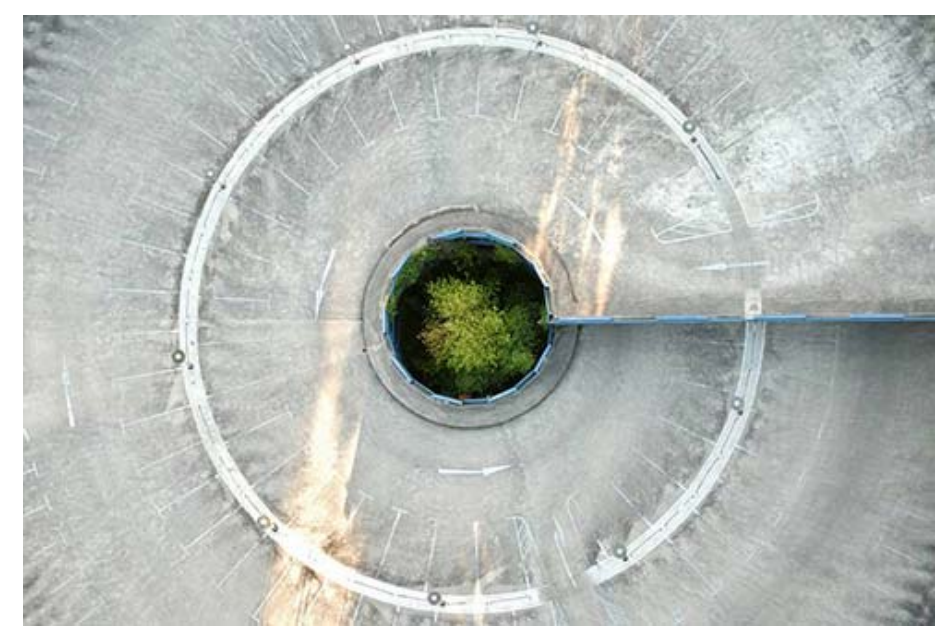

Fig. 4. Bernd Uhde (2009). Urban Surface.

(Foto: VV.AA (2011), In between, Stuttgart, DAM, p. 58)

Si perpendicularmente la fotografía puede sumergirnos en una ciudad densa, sin aire, también posee los recursos necesarios para hacerlo, paradójicamente, desde el cielo. Las vistas aéreas, que en la historia quedaron asociadas a una 
auténtica revolución en el punto de vista y en las posibilidades de composición de la imagen (Sougez (coord.); García Felguera; Pérez Gallardo; Vega, 2007: 315), son hoy medio habitual de denuncia y de llamada de atención sobre los cambios radicales que las sociedades humanas están ocasionando a la Tierra y que tienen su reflejo en las modificaciones de su superficie. A nivel de la propia forma urbana, la compresión focal y la abstracción características de estas tomas elaboran escenarios planos, de profundidad desaparecida, dibujados por una aséptica geometría y un descarnado cromatismo. Las cubiertas y los aparcamientos del proyecto Urban Surface del fotógrafo alemán Bernd Uhde, son piezas de una cartografía inanimada y epidérmica.

O todo lo contrario. Entre los lugares más visitados últimamente por los fotógrafos cualquier persona próxima al medio citaría los espacios en desuso y las edificaciones en ruinas; lo obsoleto como espectáculo, la desolación y el abandono de un tiempo que se asume solo por ajeno. Detroit se ha convertido en auténtico destino de peregrinación en estas rutas de la desocupación. Pero no son sólo las grandes fábricas, antes emblemas construidos de los años de esplendor del desarrollo, o las viviendas abandonadas por una población reducida a más de la mitad, los objetivos codiciados por los cazadores de imágenes. La ciudad en sí misma es a la vez escenario y protagonista. Habituados a gestionar el fenómeno urbano en su dimensión multiplicadora, la contracción y la disolución se presentan como procesos inauditos, cuyos parámetros de reconducción se desconocen. Mientras, nuestro sensor colectivo sigue almacenando, en número creciente, estos vacíos sobrevenidos, esta invasión de aire que miramos con incómoda ansiedad.

Si el Detroit que retrata Vergara estamos seguros de que fue ciudad, no podríamos decir lo mismo de los emplazamientos donde fueron tomadas por Roel Jacobs esas otras vistas de casas aisladas, composiciones directas en su discurso y en su mensaje, que nos ofrecen la nada como antónimo de ciudad. La gran extensión de aire que se desborda por los cuatro lados del fotograma y que ancla la mirada del espectador en un único centro: la vivienda, algo onírico, irreal, de un tiempo detenido o de un país fantástico. Sea producto del estallido de alguna burbuja, o de nuevas formas residenciales para seres desconocidos, lo cierto es que son leídas como testimonio de la desaparición de la ciudad. 


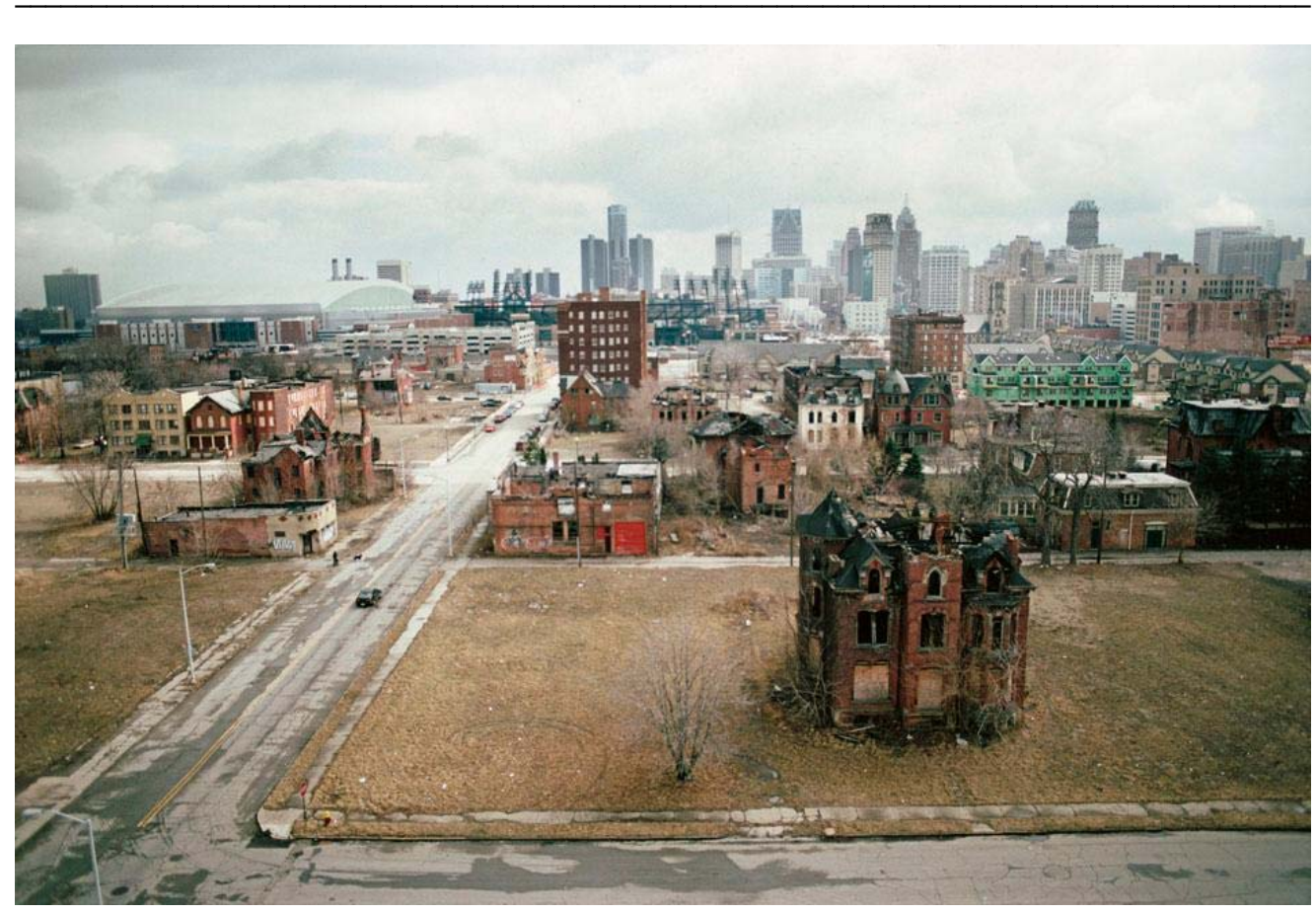

Fig. 5. Camilo José Vergara. John R. Street, Detroit, 2003 (www.camilojosevergara.com)
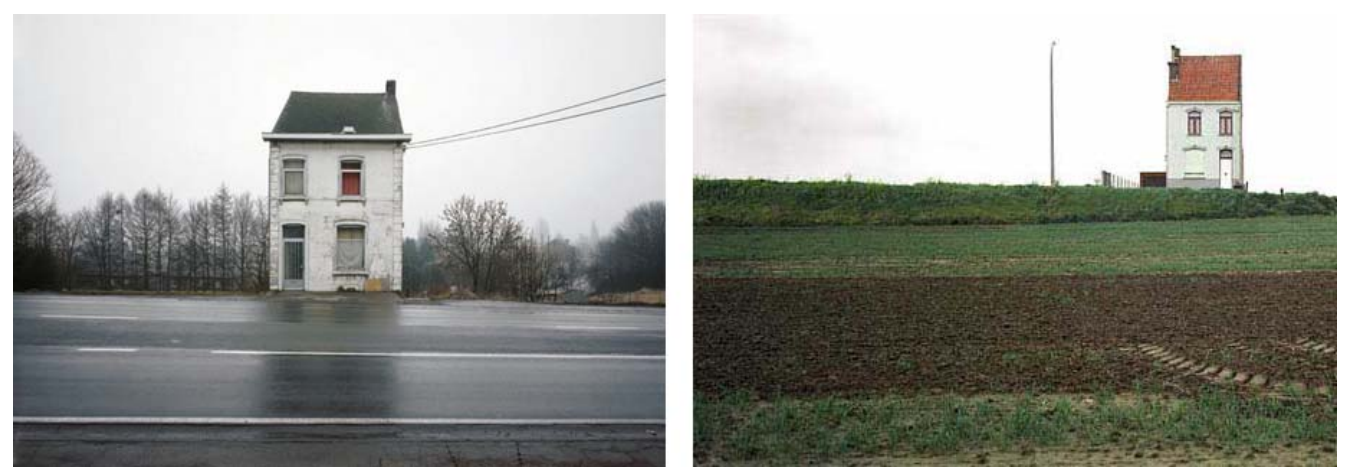

Fig. 6. Roel Jacobs (2012) Isolated Rowhouses

(JACOBS, Roel, Isolated Rowhouses, (2012), Bruxelles, Husson)

Sería desproporcionado concluir que esta doble alternativa de pesadilla, de asfixia o de hiperventilación, define la producción de imágenes urbanas en la actualidad. En cierto modo, no estaríamos haciendo más que prolongar el in- 
tento de imaginar en qué se va a convertir el fenómeno urbano, como aconsejaba Georges Perec en el último de sus ejercicios para entender la ciudad (Perec, 2012: 130). Entre otras cosas, porque siguen vigentes hoy corrientes como la Street Photography, que van reactualizándose y encontrando nuevas formas expresivas. Pero con el aire situado en el foco de nuestra atención, tendría que ser el momento de plantearnos la correspondencia entre estas líneas de fuerza de la creación visual y su reflejo como maneras de vivir lo urbano. Porque si una imagen es la representación de una percepción, con todas las implicaciones sociales de producción y comunicación (Tagg, 1988), deberíamos preguntarnos por las causas perceptivas de semejante polaridad de vacíos.

Quizás sea, como señaló hace tiempo Lipovetsky (Lipovetsky, 2003), porque nuestra época recoge la contradictoria aspiración de la hiperindividualidad, afirmada en la negación de lo colectivo, una era de narcisismo y angustia. Más aún, la fuerza de mensajes como los que acabamos de referir nos llevaría a formular la cuestión de en qué medida estos tópicos visuales, que pertenecen ya al universo de imágenes mentales de comprensión colectiva, están construyendo nuevos modos de percepción de lo urbano, tanto en el sentido de la densidad como en el de la desocupación.

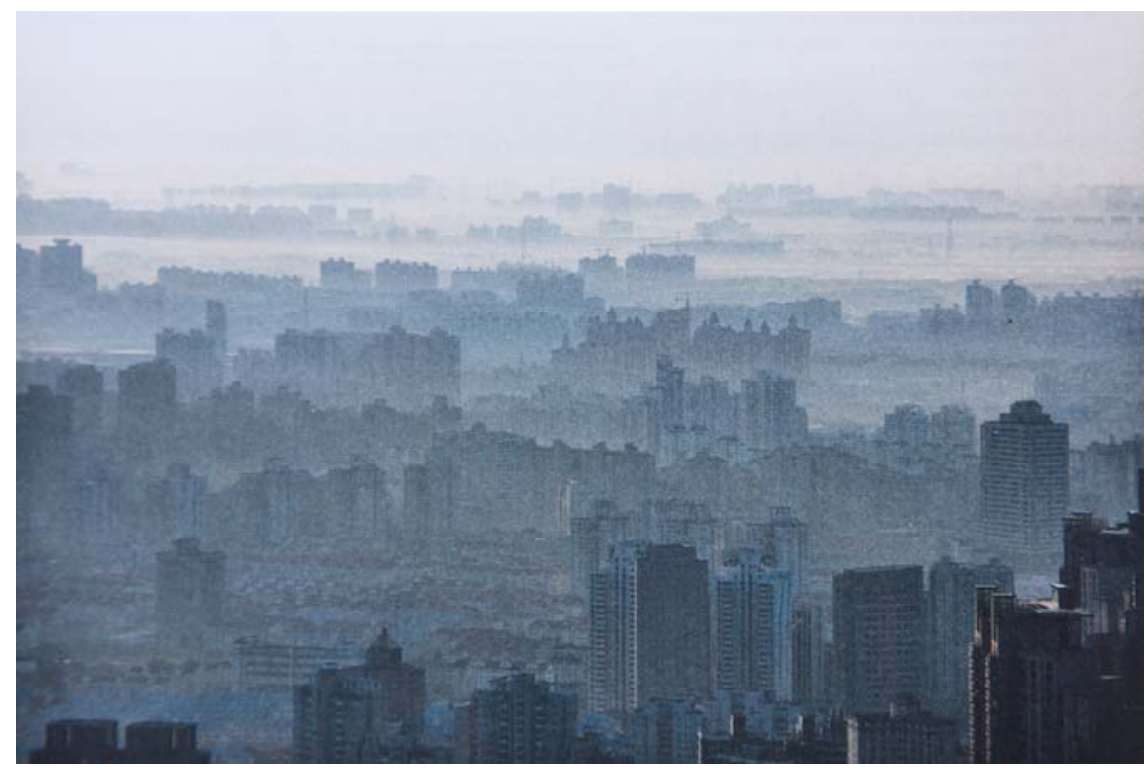

Imagen 7. Hans-Georg Esch (2009), Shanghai 17.

(VV.AA. (2011), High Rise Idea and Reality, Ostfildern, Hatje Cantz Verlag, p. 106) 


\section{Bibliografia:}

CALVINO, Italo (2005), Las ciudades invisibles, Madrid, Siruela.

JACOBS, Roel (2012), Isolated Rowhouses, Bruxelles, Husson.

LIPOVETSKY, Gilles (2003), La era del vacío. Ensayos sobre el individualismo contemporáneo, Barcelona, Anagrama.

PEREC, Georges (2012), Espèces d'espaces, Mayenne, Éditions Galilée.

QUeTGLÁs, Josep (2001), Pasado a limpio II, Valencia: Pretextos.

SOUGeZ, Marie-Loup (coord.); GArcía FElguerA, Ma de los Santos; PÉREZ

GALlARDO, Helena; VEGA, Carmelo (2007), Historia general de la fotografía, Madrid, Cátedra.

TAGG, John (1988), El peso de la representación, Barcelona, Gustavo Gili.

Vv.AA. (2011), High Rise Idea and Reality, Ostfildern, Hatje Cantz Verlag.

VV.AA. (2011), Dazwischen / In between, Stuttgart, DAM.

WOLF, Michael (2012), Architecture of density, Berlin, Peperoni books. 